\title{
Technical Note: An empirical algorithm estimating dry deposition velocity of fine, coarse and giant particles
}

\author{
L. Zhang and Z. He \\ Air Quality Research Division, Science and Technology Branch, Environment Canada, Toronto, Canada \\ Correspondence to: L. Zhang (leiming.zhang@ec.gc.ca)
}

Received: 24 September 2013 - Published in Atmos. Chem. Phys. Discuss.: 2 December 2013

Revised: 12 February 2014 - Accepted: 6 March 2014 - Published: 11 April 2014

\begin{abstract}
An empirical algorithm is developed for calculating bulk dry deposition velocity $\left(V_{\mathrm{d}}\right)$ of fine $\left(\mathrm{PM}_{2.5}-\right.$ particles having a diameter of $\leq 2.5 \mu \mathrm{m})$, coarse $\left(\mathrm{PM}_{2.5-10}-\right.$ particles having a diameter of $2.5-10 \mu \mathrm{m})$, and giant $\left(\mathrm{PM}_{10+}\right.$ - particles having a diameter of $>10 \mu \mathrm{m}$ ) atmospheric particles. The algorithm is developed from an empirical fit of $V_{\mathrm{d}}$ data calculated using the size-resolved $V_{\mathrm{d}}$ scheme of Zhang et al. (2001) with assumed lognormal size distributions of $\mathrm{PM}_{2.5}, \mathrm{PM}_{2.5-10}$ and $\mathrm{PM}_{10+}$. In the new algorithm, the surface deposition velocity $\left(V_{\mathrm{ds}}\right)$ is parameterized as a simple linear function of friction velocity $\left(u_{*}\right)$ for $\mathrm{PM}_{2.5}$ and as a polynomial function of $u_{*}$ for both $\mathrm{PM}_{2.5-10}$ and $\mathrm{PM}_{10+}$ over all the 26 land use categories (LUCs). An adjustment factor as an exponential function of $u_{*}$ and leaf area index (LAI) is also applied to $V_{\mathrm{ds}}$ of $\mathrm{PM}_{2.5-10}$ and $\mathrm{PM}_{10+}$ over 9 of the 26 LUCs that have variable LAI. Constant gravitational settling velocities are provided for $\mathrm{PM}_{2.5}, \mathrm{PM}_{2.5-10}$ and $\mathrm{PM}_{10+}$. Aerodynamic resistance between a reference height and the surface can be calculated using available analytical formulas from the literature. The bulk $V_{\mathrm{d}}$ of $\mathrm{PM}_{2.5}$, $\mathrm{PM}_{2.5-10}$ and $\mathrm{PM}_{10+}$ at the reference height can then be calculated by combining the gravitational settling velocity, aerodynamic resistance and the parameterized $V_{\mathrm{ds}}$. $V_{\mathrm{d}}$ values calculated using the new algorithm are within $\pm 20 \%$ of those using the original size-resolved scheme for fine, coarse and giant particles. Uncertainties in $V_{\mathrm{d}}$ values from the new algorithm due to the pre-assumed size distributions are on the order of $20 \%$ for fine particles and on the order of a factor of 2.0 for coarse and giant particles. The new algorithm provides an alternative approach for calculating $V_{\mathrm{d}}$ of bulk aerosol particles. $V_{\mathrm{d}}$ of any particulate species can be simply estimated using this scheme as long as the mass fractions in fine, coarse and giant particles are known or can be assumed.
\end{abstract}

\section{Introduction}

The parameter known as dry deposition velocity $\left(V_{\mathrm{d}}\right)$ has been commonly used in chemical transport models as well as in monitoring networks to associate a chemical species' mass flux density to the surface with its ambient concentration (i.e., a species' flux is a product of its $V_{\mathrm{d}}$ and its ambient concentration). Knowledge of $V_{\mathrm{d}}$ for atmospheric particles can be found in previous review papers (Sehmel, 1980; Nicholson, 1988; Sievering, 1989; Ruijgrok et al., 1995; Gallagher et al., 1997; Zufall and Davidson, 1998; Zhang and Vet, 2006; Petroff et al., 2008; Pryor et al., 2008; Fowler et al., 2009; Nemitz, 2012). $V_{\mathrm{d}}$ for atmospheric particles strongly depends on particle size, among other factors. In most air quality and climate studies where both particle number and mass concentrations need to be considered, a size-resolved particle dry deposition scheme (e.g., Sehmel and Hodgson, 1980; Giorgi., 1986; Zhang et al., 2001; Nho-Kim et al., 2004; Feng, 2008; Petroff and Zhang, 2010; Kouznetsov and Sofiev, 2012) is needed. However, in many environmental assessments the dry deposition flux of a pollutant or a group of pollutants of interest to various ecosystems is the only concern. In this case, a simple empirical formula of $V_{\mathrm{d}}-$ or the so-called bulk $V_{\mathrm{d}}$ algorithm - combined with monitored air mass concentrations is sufficient.

Several size-resolved $V_{\mathrm{d}}$ schemes are available in the literature that can be applied to any particle species and over any different surfaces (Zhang and Vet, 2006). However, no "universal" $V_{\mathrm{d}}$ scheme is available for bulk aerosol particles, which are monitored in various atmospheric deposition networks. Wesely et al. (1985) derived an empirical bulk $V_{\mathrm{d}}$ formula for sulfate particles using sulfate flux data over grassland, and this formula was later widely applied to sulfate 
as well as to many other fine particle species over various surface types. Other empirical formulas were also developed at later times for various particle species and/or size ranges. For example, Ruijgrok et al. (1997) generated a bulk $V_{\mathrm{d}}$ formula for water-soluble inorganic ions, which include species of both fine and coarse particles, using flux data over forest canopies, and Laumaud et al. (1994) and Gallagher et al. (2002) derived formulas for submicron particles. None of these bulk $V_{\mathrm{d}}$ formulas can be considered as universally applicable (e.g., to any particle species or over any different surfaces).

The present study aims to fill this gap by developing a bulk $V_{\mathrm{d}}$ algorithm taking the size-resolved $V_{\mathrm{d}}$ scheme of Zhang et al. (2001) as the benchmark. The reasons for choosing the scheme of Zhang et al. (2001) as the benchmark are that (1) it is a widely used scheme in the community, (2) it can be applied to any surface types, and (3) it seems to predict reasonable $V_{\mathrm{d}}$ for most particle size ranges and over most surface types. The scheme might overpredict $V_{\mathrm{d}}$ of small particles (e.g., $<0.1 \mu \mathrm{m}$ ) over smooth surfaces (Petroff and Zhang, 2010). However, small particles have very low mass fractions and thus small contributions to the bulk $V_{\mathrm{d}}$. Following the findings of Zhang et al. (2012), the new algorithm should be developed for calculating $V_{\mathrm{d}}$ of $\mathrm{PM}_{2.5}, \mathrm{PM}_{2.5-10}$ and $\mathrm{PM}_{10+}$, instead of for specific particle species, and be applicable to various natural surfaces. The new algorithm is expected to produce similar $V_{\mathrm{d}}$ values to the original sizeresolved scheme, but is much easier to implement at atmospheric deposition monitoring networks.

\section{Methodology}

Particle dry deposition velocity can be calculated according to (Slinn, 1982; Zhang et al., 2001; Gallagher et al., 2002)

$V_{\mathrm{d}}=V_{\mathrm{g}}+\frac{1}{R_{\mathrm{a}}+R_{\mathrm{S}}}$,

where $V_{\mathrm{g}}$ is the gravitational settling velocity, $R_{\mathrm{a}}$ is the aerodynamic resistance above the canopy, and $R_{\mathrm{S}}$ is the surface resistance. Note that the inverse of $R_{\mathrm{S}}$ is also referred to as surface deposition velocity $\left(V_{\mathrm{ds}}\right)$ (Gallagher et al., 2002; Petroff and Zhang, 2010). Equation (1) applies to both bulk and size-segregated $V_{\mathrm{d}}$. Theoretically, a bulk $V_{\mathrm{d}}$ should be obtained by integrating size-segregated $V_{\mathrm{d}}$ according to particle size distribution. Considering that $R_{\mathrm{a}}$ does not change with particle size and simple analytical formulas are available in the literature for calculating $R_{\mathrm{a}}$, an alternative approach would be to first obtain a bulk $V_{\mathrm{ds}}$ and a bulk $V_{\mathrm{g}}$; the bulk $V_{\mathrm{d}}$ can then be obtained from using Eq. (1). Parameterizing a bulk $V_{\mathrm{ds}}$ and a bulk $V_{\mathrm{g}}$ would be much simpler than parameterizing a bulk $V_{\mathrm{d}}$ due to the avoidance of $R_{\mathrm{a}}$ (and thus the parameters characterizing the planetary boundary layer). Note that although $V_{\mathrm{g}}$ depends strongly on particle size, it only changes slightly with particle density and ambient tem-

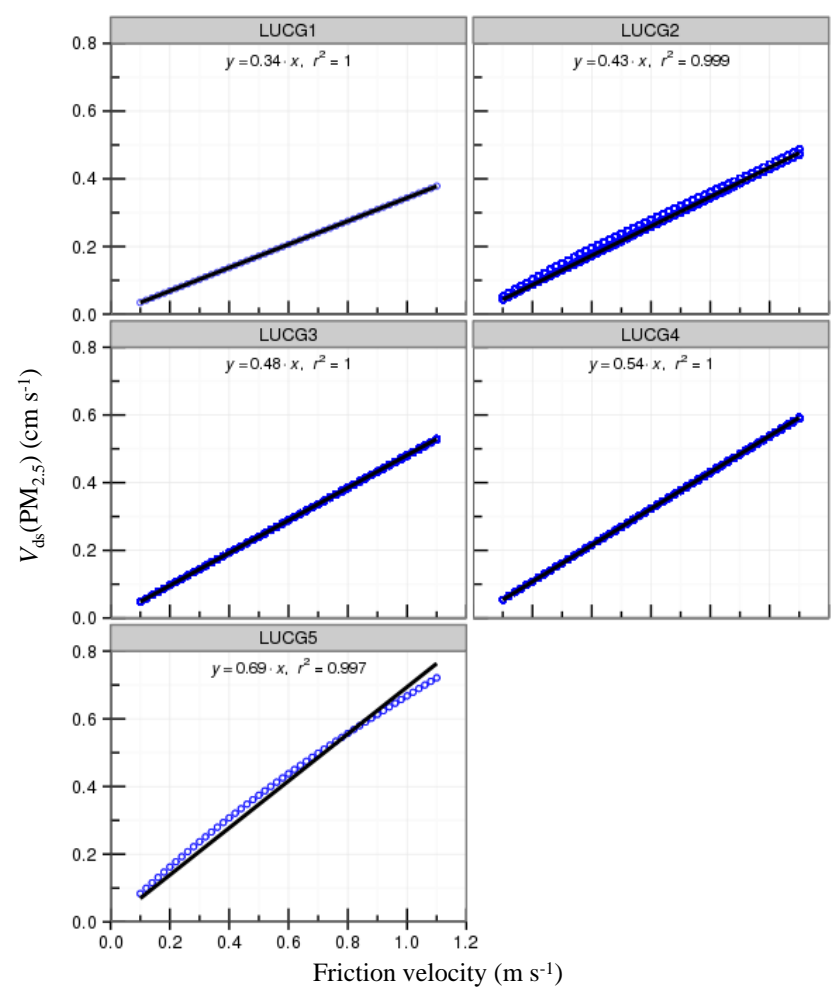

Fig. 1. Bulk $V_{\mathrm{ds}}\left(\mathrm{PM}_{2.5}\right)$ as a function of $u_{*}$ for five group LUCs. Solid lines represent regression equations, and circles represent data points.

perature; a constant value can thus be used for a fixed particle size or size distribution.

The size-resolved particle dry deposition scheme of Zhang et al. (2001) was used to derive $V_{\mathrm{ds}}$ values for any particle size. The size-segregated $V_{\mathrm{ds}}$ was then integrated to obtain bulk $V_{\mathrm{ds}}$ for $\mathrm{PM}_{2.5}, \mathrm{PM}_{2.5-10}$ and $\mathrm{PM}_{10+}$ assuming a lognormal size distribution for each of the three size ranges. The geometric mass median diameter $\left(d_{\mathrm{m}}\right)$ and geometric standard deviation $(\sigma)$ were chosen as $0.4 \mu \mathrm{m}$ and 2.2 , respectively, for $\mathrm{PM}_{2.5} ; 4.5 \mu \mathrm{m}$ and 1.6 for $\mathrm{PM}_{2.5-10}$; and $20 \mu \mathrm{m}$ and 1.6 for $\mathrm{PM}_{10+}$. Regression equations were then generated using the bulk $V_{\mathrm{ds}}$ data.

The original version of Zhang et al. (2001) used 15 land use categories (LUCs) and was later extended to 26 LUCs, consistent with those used in Zhang et al. (2003) (see Supporting Information of Zhang et al., 2012). The 26 LUCs were also used in the present study, although they were put into different groups (Sect. 3.1) or categories (Sects. 3.2 and 3.3) for easy presentation. According to Zhang et al. (2001), $V_{\mathrm{ds}}$ was calculated as

$V_{\mathrm{ds}}=\varepsilon_{0} u_{*}\left(E_{\mathrm{B}}+E_{\mathrm{IM}}+E_{\mathrm{IN}}\right) R_{1}$,

where $\varepsilon_{0}$ is an empirical constant (taken as 3.0 ), $u_{*}$ is friction velocity, $E_{\mathrm{B}}, E_{\mathrm{IM}}, E_{\mathrm{IN}}$ are collection efficiency from Brownian diffusion, impaction and interception, respectively, 


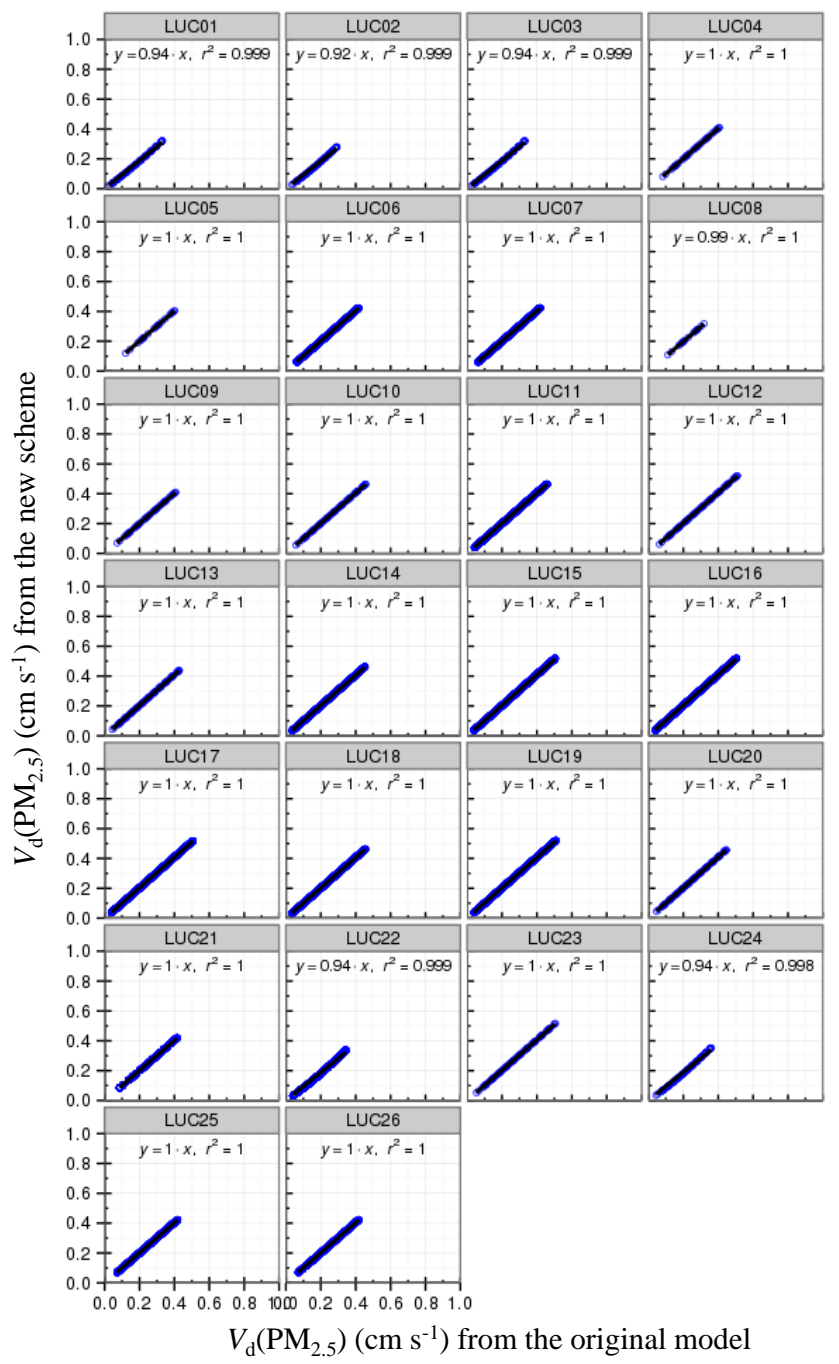

Fig. 2. A comparison of $V_{\mathrm{d}}\left(\mathrm{PM}_{2.5}\right)$ between the new and the original scheme for the 26 LUCs. Solid lines represent regression equations, and circles represent data points.

and $R_{1}$ is the correction factor representing the fraction of particles that stick to the surface (taken as 1.0 in this study, which means no particle rebound is considered). $V_{\mathrm{ds}}$ only depends on $u_{*}$ and LUC-specific parameters. Thus, the bulk $V_{\mathrm{ds}}$ can be parameterized as a function of $u_{*}$ for each LUC with the possibility of including additional LUC-specific parameters (e.g., leaf area index - LAI, which changes with time of the year for some LUCs).

$V_{\mathrm{g}}$ depends strongly on particle size, only slightly on particle density and meteorological conditions, but not on LUC. Thus, a constant $V_{\mathrm{g}}$ can be used for a fixed particle size distribution. $V_{\mathrm{g}}$ was also calculated using the same lognormal size distributions mentioned above, and values of $3.7 \times 10^{-5}$, $1.8 \times 10^{-3}$ and $3.4 \times 10^{-2} \mathrm{~m} \mathrm{~s}^{-1}$ were obtained for $\mathrm{PM}_{2.5}$, $\mathrm{PM}_{2.5-10}$ and $\mathrm{PM}_{10+}$, respectively, when choosing a particle density of $2.0 \mathrm{~g} \mathrm{~cm}^{-3}$ and a temperature of $15^{\circ} \mathrm{C}$. $V_{\mathrm{g}}$ could

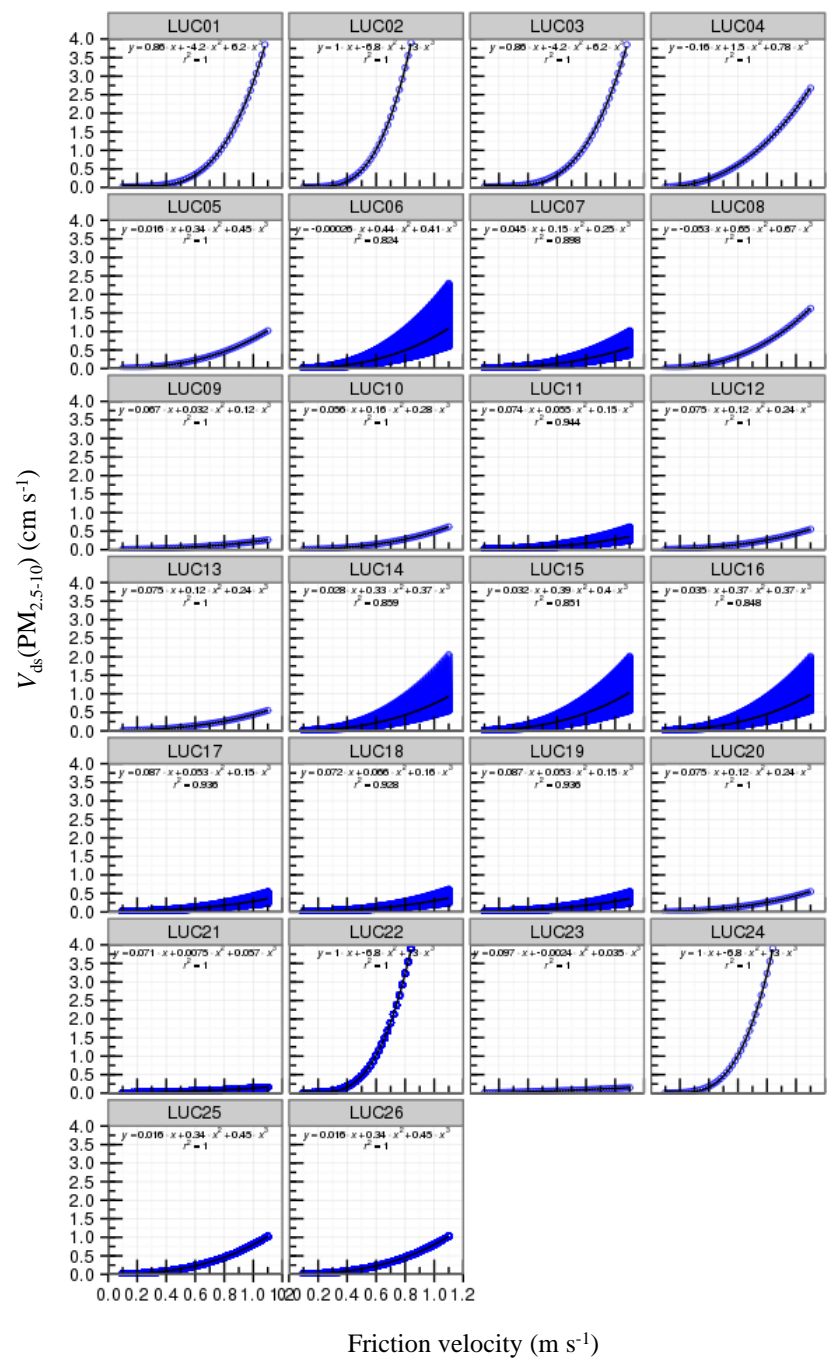

Fig. 3. Bulk $V_{\mathrm{ds}}\left(\mathrm{PM}_{2.5-10}\right)$ as a function of $u_{*}$. Solid lines represent regression equations, and circles represent data points.

vary by $10-20 \%$ if temperature increased or decreased by $20^{\circ} \mathrm{C}$. $V_{\mathrm{g}}$ is not discussed in Sect. 3 , and only $V_{\mathrm{ds}}$ was described. Note that a particle density of $2.0 \mathrm{~g} \mathrm{~cm}^{-3}$ was used throughout the study.

\section{Development and validation of the new algorithm}

\section{1 $\mathbf{P M}_{2.5}$}

The bulk $V_{\mathrm{ds}}$ for $\mathrm{PM}_{2.5}$ as a function of $u_{*}$ was generated for all the 26 LUCs (figure not provided). Regression analysis suggested that $V_{\mathrm{ds}}\left(\mathrm{m} \mathrm{s}^{-1}\right)$ for $\mathrm{PM}_{2.5}$ can be parameterized as a simple linear function of $u_{*}\left(\mathrm{~m} \mathrm{~s}^{-1}\right)$ over all the LUCs:

$V_{\mathrm{ds}}=a_{1} u_{*}$,

where $a_{1}$ is the LUC-dependent empirical constant. If LUCs with similar $a_{1}$ values are grouped together, the original 26 

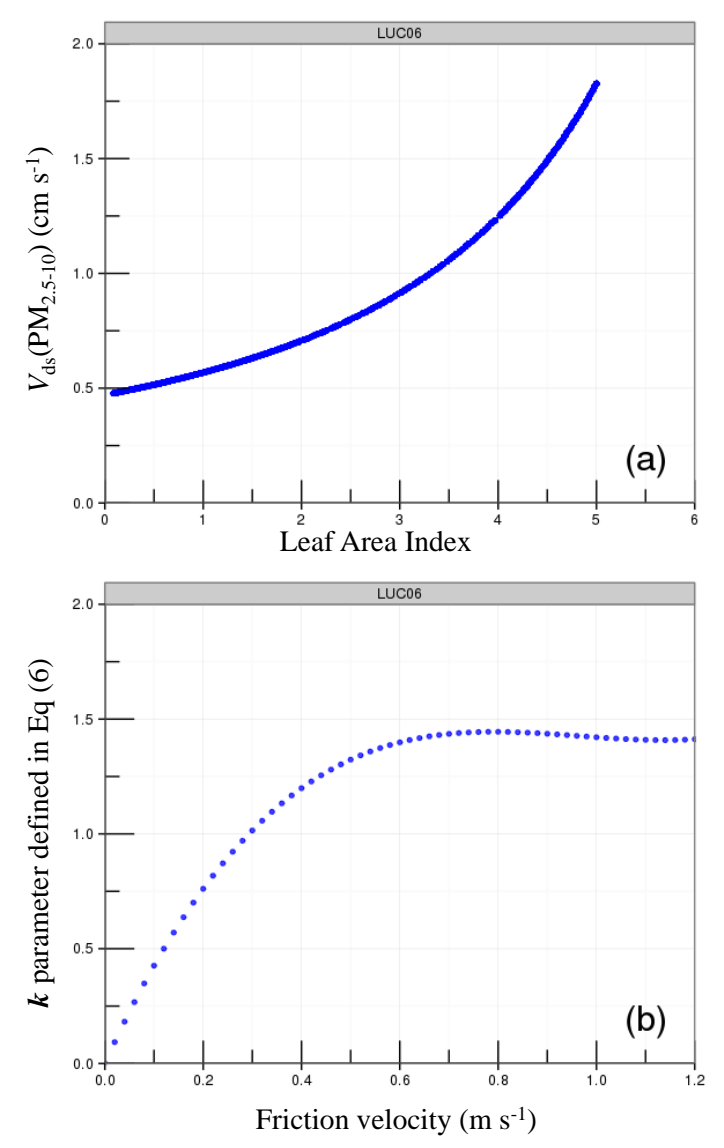

Fig. 4. (a) Bulk $V_{\mathrm{ds}}\left(\mathrm{PM}_{2.5-10}\right)$ vs. LAI under a fixed $u_{*}$ $\left(1.0 \mathrm{~m} \mathrm{~s}^{-1}\right)$ for LUC 6 , and (b) $k$ (defined in Eq. 6) vs. $u_{*}$ for LUC 6.

LUCs can be regrouped into five groups (Fig. 1 and Table 1). $a_{1}$ ranged from 0.0034 to 0.0069 for the five groups. Note that in the figures $V_{\mathrm{ds}}$ is in $\mathrm{cm} \mathrm{s}^{-1}$ for easy plotting; $a_{1}$ values shown in the figures were divided by 100 when applying to Eq. (3). These values are similar to (although slightly larger than) those found in previous studies that focused on dry deposition of fine particles (see Table 1 of Gallagher et al., 2002, for a summary of earlier studies).

The bulk $V_{\mathrm{d}}$ for $\mathrm{PM}_{2.5}$ can then be calculated as

$V_{\mathrm{d}}\left(\mathrm{PM}_{2.5}\right)=V_{\mathrm{g}}\left(\mathrm{PM}_{2.5}\right)+\frac{1}{R_{\mathrm{a}}+1 /\left(a_{1} u_{*}\right)}$.

Note that $V_{\mathrm{g}}\left(\mathrm{PM}_{2.5}\right)$ is on the order of $10^{-5} \mathrm{~m} \mathrm{~s}^{-1}$ (see Sect. 2), much smaller than the second term (e.g., $10^{-4}$ to $10^{-3} \mathrm{~m} \mathrm{~s}^{-1}$ ) in Eq. (4) under typical $u_{*}$ values, and thus can be omitted for simplicity if preferred. Apparently, the main difference between the new (Eq. 4) and the original scheme (Eq. 1) is the different averaging procedure of sizesegregated deposition velocity $\left(V_{\mathrm{ds}}\right.$ vs. $\left.V_{\mathrm{d}}\right)$.

A comparison of $V_{\mathrm{d}}\left(\mathrm{PM}_{2.5}\right)$ between the new (Eq. 4) and the original scheme (Eq. 1) was performed using $a_{1}$ values generated from Fig. 1. In this comparison, $V_{\mathrm{d}}\left(\mathrm{PM}_{2.5}\right)$ from the original scheme was obtained from integrating the sizesegregated $V_{\mathrm{d}}\left(\right.$ not $\left.V_{\mathrm{ds}}\right)$ using the same lognormal size distribution mentioned above. $R_{\mathrm{a}}$ and $u_{*}$ were the same in the two schemes and were generated by varying day of the year (for covering different LAI values), wind speed $\left(2-12 \mathrm{~m} \mathrm{~s}^{-1}\right)$, and temperature differences between the reference height and the surface (for covering stable, neutral and unstable turbulent conditions). As shown in Fig. 2, the two schemes basically produced the same results over all the rough surfaces. It is worth pointing out that $R_{\mathrm{a}}$ is generally much smaller than surface resistance (the inverse of $V_{\mathrm{ds}}$ ) over rough surface, so the different averaging procedures from the above two schemes caused little differences in their final $V_{\mathrm{d}}$ values. For smooth surfaces (LUCs 1, 2, 3, 22 and 24), $V_{\mathrm{d}}\left(\mathrm{PM}_{2.5}\right)$ produced from the new algorithm was a few percent $(6-8 \%)$ 


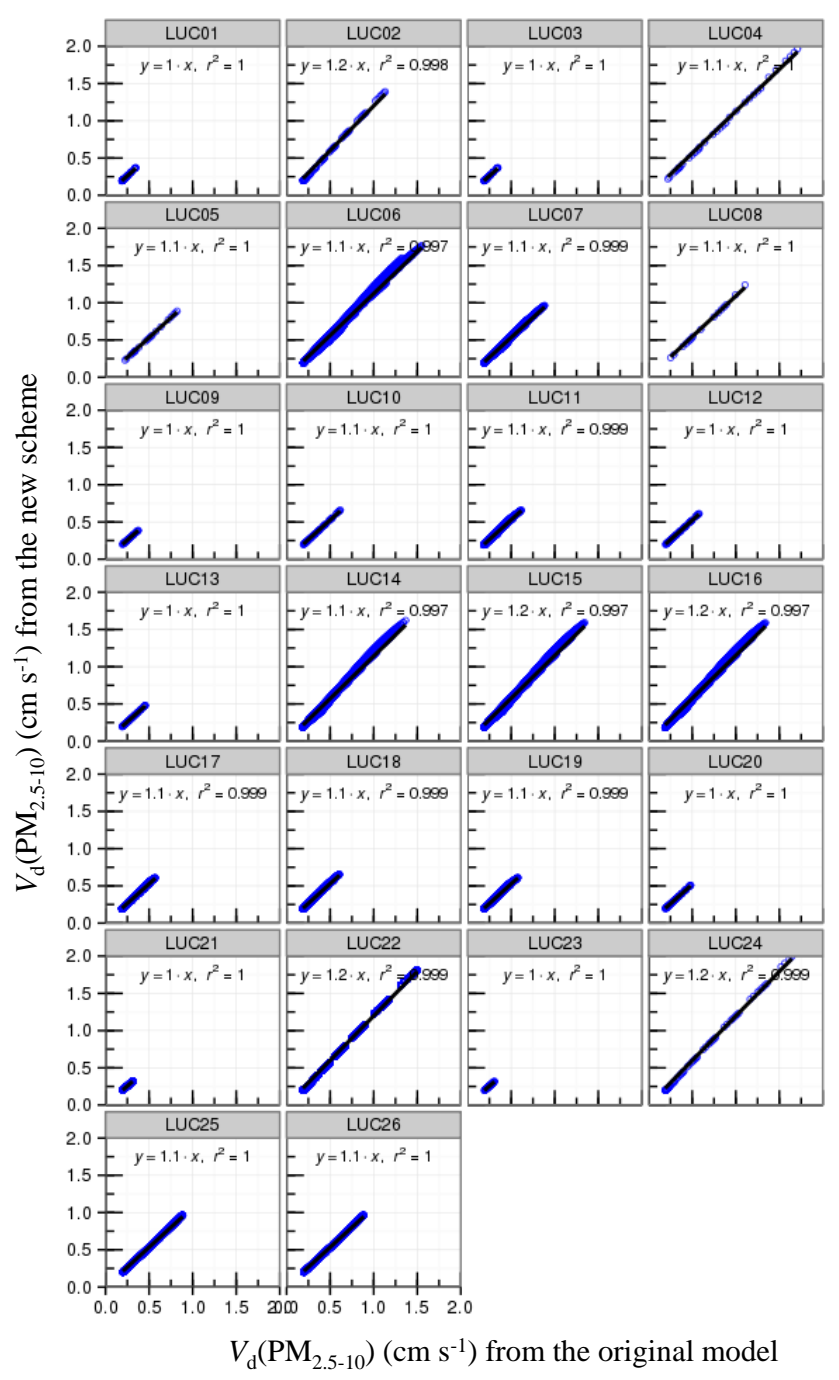

Fig. 5. Same as in Fig. 2 except for $V_{\mathrm{d}}\left(\mathrm{PM}_{2.5-10}\right)$.

smaller than that from the original scheme, but this was thought to be acceptable considering that the original scheme likely overpredicted $V_{\mathrm{d}}$ for small particles over smooth surfaces (Petroff and Zhang, 2010). The slight differences in the results between the smoother and the rougher surfaces were caused by the different $R_{\mathrm{a}}$ values over these surfaces because $R_{\mathrm{a}}$ was much larger over smoother surfaces (due to smaller roughness lengths) under the same wind speed conditions.

\section{2 $\quad \mathrm{PM}_{2.5-10}$}

The bulk $V_{\mathrm{ds}}$ for $\mathrm{PM}_{2.5-10}$ as a function of $u_{*}$ was also generated for all the 26 LUCs (Fig. 3). It was found that, for a fixed $u_{*}$ value, only one $V_{\mathrm{ds}}$ value was generated for some LUCs, but multiple values were obtained for the other LUCs. The former case was for LUCs with a constant LAI (including 0 value) (i.e., LUCs $1-5,8-10,12-13,20,23-24)$ or with an LAI varying in a narrow range (i.e., LUCs $21-22,25-$
26) (referred to category 1 below) while the latter case was for LUCs with variable LAI (i.e., LUCs 6-7, 11, 14-19) (referred to category 2 below). Daily variations of LAI for each LUC can be found in Zhang et al. (2003). Regression analysis shows high coefficient of determination (with $R^{2}>0.82$ ) between $V_{\mathrm{ds}}$ and $u_{*}$ if a polynomial function (power of 3 ) for all the LUCs is used.

Based on regression equations shown in Fig. $3, V_{\mathrm{ds}}$ can be simply parameterized as a function of $u_{*}$ for category 1 LUCs:

$V_{\mathrm{ds}}\left(\mathrm{PM}_{2.5-10}\right)=b_{1} u_{*}+b_{2} u_{*}^{2}+b_{3} u_{*}^{3}$,

where $b_{1}, b_{2}$ and $b_{3}$ are the LUC-dependent empirical constants and are listed in Table 2a. Note that in Fig. 3, $V_{\mathrm{ds}}$ is in $\mathrm{cm} \mathrm{s}^{-1}$ for easy plotting; $b_{1}, b_{2}$ and $b_{3}$ values shown in the figures were divided by 100 when applying to Eq. (5).

Equation (5) also fits well to category 2 LUCs if the LAI value does not change. Taking LUC 6 as an example, the top curve represents $V_{\mathrm{ds}}$ under maximum LAI (LAI $\mathrm{Lax}_{\max }$ ) condition and the bottom curve for minimum LAI condition. For a fixed $u_{*}$, an exponential increase in $V_{\mathrm{ds}}$ was found with increasing LAI (Fig. 4a). Thus, Eq. (5) was first used to parameterize $V_{\mathrm{ds}}$ for maximum LAI for each category 2 LUC. An adjustment factor as an exponential function of LAI was then added to Eq. (5) for different LAI conditions. The new equation becomes

$V_{\mathrm{ds}}\left(\mathrm{PM}_{2.5-10}\right)=\left(b_{1} u_{*}+b_{2} u_{*}^{2}+b_{3} u_{*}^{3}\right) e^{k\left(\frac{\mathrm{LAI}}{\mathrm{LA} \max }-1\right)}$.

The parameter $k$ in the above equation was found to change with $u_{*}$. Thus, $k$ values were generated as a function of $u_{*}$ using the data shown in Fig. 3. $k$ values for LUC 6 were shown in Fig. $4 \mathrm{~b}$ as an example. Coincidently $k$ can also be fitted into a polynomial function of $u_{*}$ :

$k=c_{1} u_{*}+c_{2} u_{*}^{2}+c_{3} u_{*}^{3}$,

where $c_{1}, c_{2}$ and $c_{3}$ are the LUC-dependent empirical constants. $b_{1}, b_{2}, b_{3}, c_{1}, c_{2}$ and $c_{3}$ for Category 2 LUCs are shown in Table $2 \mathrm{~b}$. The final equation for $V_{\mathrm{ds}}$ becomes

$V_{\mathrm{ds}}\left(\mathrm{PM}_{2.5-10}\right)=$

$\left(b_{1} u_{*}+b_{2} u_{*}^{2}+b_{3} u_{*}^{3}\right) e^{\left(c_{1} u_{*}+c_{2} u_{*}^{2}+c_{3} u_{*}^{3}\right)\left(\frac{\mathrm{LAI}}{\mathrm{LAI} \max }-1\right)}$.

The bulk $V_{\mathrm{d}}$ for $\mathrm{PM}_{2.5-10}$ can then be calculated as

$V_{\mathrm{d}}\left(\mathrm{PM}_{2.5-10}\right)=V_{\mathrm{g}}\left(\mathrm{PM}_{2.5-10}\right)+\frac{1}{R_{\mathrm{a}}+1 / V_{\mathrm{ds}}\left(\mathrm{PM}_{2.5-10}\right)}$.

A comparison of $V_{\mathrm{ds}}\left(\mathrm{PM}_{2.5-10}\right)$ from using Eqs. (5) and (8) and from the original scheme is conducted with assumed $u_{*}$ (figure not provided). $V_{\mathrm{ds}}\left(\mathrm{PM}_{2.5-10}\right)$ values calculated using the newly developed equations agree very well with those using the original scheme with differences of $\sim 10 \%$ or less over all the LUCs. No systematic difference was 

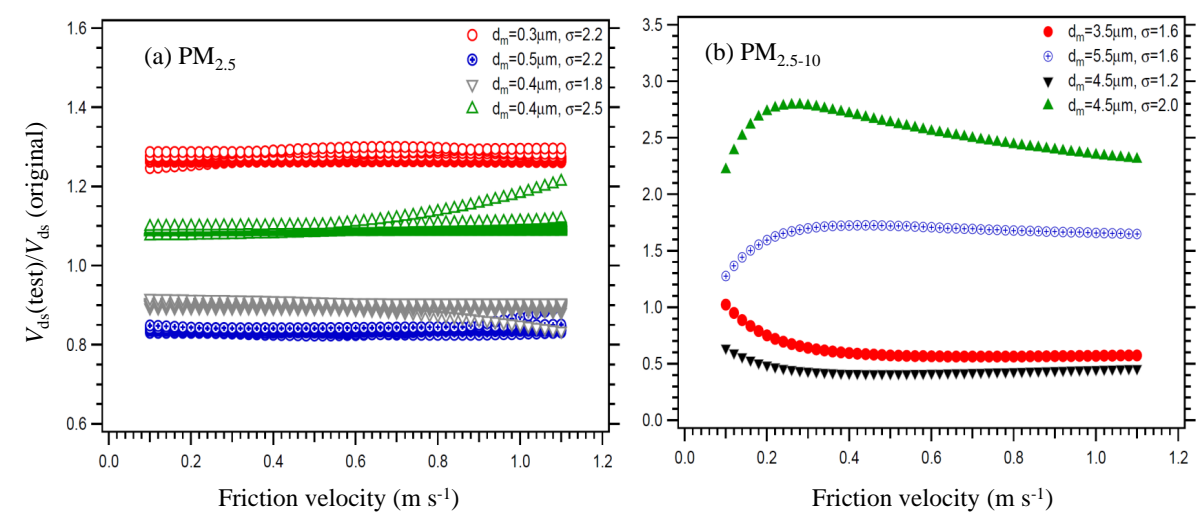

Fig. 6. The ratio of $V_{\mathrm{ds}}$ from sensitivity tests to the original $V_{\mathrm{ds}}$ vs. $u_{*}$ (a) for $\mathrm{PM}_{2.5}$ over all the LUCs and (b) for PM $2.5-10$ over LUC 4 .

Table 2a. Empirical constants (in scientific format) for use in Eqs. (5) and (10) for Category 1 LUCs.

\begin{tabular}{lcccccc}
\hline \multirow{2}{*}{ UUC } & \multicolumn{3}{c}{$V_{\mathrm{ds}}\left(\mathrm{PM}_{2.5-10}\right)$} & \multicolumn{3}{c}{$V_{\mathrm{ds}}\left(\mathrm{PM}_{10+}\right)$} \\
\cline { 2 - 6 } & $b_{1}$ & $b_{2}$ & $b_{2}$ & $d_{1}$ & $d_{2}$ & $d_{3}$ \\
\hline $\begin{array}{l}\text { 01: water } \\
\text { 03: inland lake }\end{array}$ & $2.6 \times 10^{-1}$ & $-1.3 \times 10^{0}$ & $3.0 \times 10^{0}$ & $-8.7 \times 10^{-1}$ & $-5.5 \times 10^{0}$ & $9.9 \times 10^{1}$ \\
\hline $\begin{array}{l}\text { 02: ice } \\
\text { 22: tundra }\end{array}$ & $3.9 \times 10^{-1}$ & $-3.3 \times 10^{0}$ & $8.8 \times 10^{0}$ & $-7.3 \times 10^{0}$ & $4.6 \times 10^{1}$ & $9.4 \times 10^{1}$ \\
24: desert & & & & & & \\
\hline 04: evergreen needleleaf trees & $-1.6 \times 10^{-1}$ & $1.5 \times 10^{0}$ & $7.8 \times 10^{-1}$ & $-9.8 \times 10^{-1}$ & $7.1 \times 10^{1}$ & $-9.5 \times 10^{0}$ \\
\hline $\begin{array}{l}\text { 05: evergreen broadleaf trees } \\
\text { 25: mixed wood forests }\end{array}$ & $1.6 \times 10^{-2}$ & $3.4 \times 10^{-1}$ & $4.5 \times 10^{-1}$ & $-2.2 \times 10^{0}$ & $3.9 \times 10^{1}$ & $-6.7 \times 10^{0}$ \\
26: transitional forest & & & & & & \\
\hline 08: tropical broadleaf trees & $-5.3 \times 10^{-2}$ & $6.6 \times 10^{-1}$ & $6.7 \times 10^{-1}$ & $-1.7 \times 10^{0}$ & $5.2 \times 10^{1}$ & $-1.2 \times 10^{1}$ \\
\hline 09: drought deciduous trees & $6.7 \times 10^{-2}$ & $3.2 \times 10^{-2}$ & $1.2 \times 10^{-1}$ & $-1.3 \times 10^{0}$ & $1.3 \times 10^{1}$ & $5.3 \times 10^{-1}$ \\
\hline 10: evergreen broadleaf shrub & $5.6 \times 10^{-2}$ & $1.6 \times 10^{-1}$ & $2.8 \times 10^{-1}$ & $-2.2 \times 10^{0}$ & $2.7 \times 10^{1}$ & $-2.7 \times 10^{0}$ \\
\hline 12: thorn shrubs & $7.5 \times 10^{-2}$ & $1.2 \times 10^{-1}$ & $2.4 \times 10^{-1}$ & $-2.1 \times 10^{0}$ & $2.4 \times 10^{1}$ & $-1.8 \times 10^{0}$ \\
13: short grass and forbs & & & & & & \\
\hline 20: irrigated crops & $7.1 \times 10^{-2}$ & $7.0 \times 10^{-3}$ & $5.7 \times 10^{-2}$ & $-7.2 \times 10^{-1}$ & $6.4 \times 10^{0}$ & $1.4 \times 10^{0}$ \\
\hline 21: urban & $9.9 \times 10^{-2}$ & $-1.3 \times 10^{-2}$ & $4.6 \times 10^{-2}$ & $-9.8 \times 10^{-2}$ & $2.1 \times 10^{0}$ & $3.3 \times 10^{0}$ \\
\hline 23: swamp & & & &
\end{tabular}

identified when considering all the LUCs together. Note that $V_{\mathrm{g}}\left(\mathrm{PM}_{2.5-10}\right)$ was on a similar order of magnitude to $V_{\text {ds }}\left(\mathrm{PM}_{2.5-10}\right)$ under low $u_{*}$ values but was much smaller than $V_{\mathrm{ds}}\left(\mathrm{PM}_{2.5-10}\right)$ under high $u_{*}$ values.

A comparison of $V_{\mathrm{d}}\left(\mathrm{PM}_{2.5-10}\right)$ between the new algorithm (Eq. 9) and the original scheme (Eq. 1) is shown in Fig. 5, using the same input parameters (day of the year, wind speed, and temperature) as was used for $\mathrm{PM}_{2.5}$. The differences in $V_{\mathrm{d}}\left(\mathrm{PM}_{2.5-10}\right)$ between the new and the old scheme were within $10 \%$ over all the LUCs except LUCs 2, 15, 22 and 24 for which the differences were up to $20 \%$. Considering the large uncertainties in any existing dry deposition schemes, the differences of $20 \%$ or smaller were considered acceptable.

\section{3 $\mathrm{PM}_{10+}$}

The procedure generating $V_{\mathrm{ds}}$ formulas for $\mathrm{PM}_{10+}$ was similar to that of $\mathrm{PM}_{2.5-10}$. Here, only the final equations are given:

$V_{\mathrm{ds}}\left(\mathrm{PM}_{10+}\right)=d_{1} u_{*}+d_{2} u_{*}^{2}+d_{3} u_{*}^{3}$, 
Table 2b. Empirical constants for use in Eqs. (8) and (11) for Category 2 LUCs.

\begin{tabular}{|c|c|c|c|c|c|c|c|c|c|c|c|c|}
\hline \multirow[b]{2}{*}{ LUC } & \multicolumn{6}{|c|}{$V_{\mathrm{ds}}\left(\mathrm{PM}_{2.5-10}\right)$} & \multicolumn{6}{|c|}{$V_{\mathrm{ds}}\left(\mathrm{PM}_{10+}\right)$} \\
\hline & $b_{1}$ & $b_{2}$ & $b_{3}$ & $c_{1}$ & $c_{2}$ & $c_{3}$ & $d_{1}$ & $d_{2}$ & $d_{3}$ & $f_{1}$ & $f_{2}$ & $f_{3}$ \\
\hline $\begin{array}{l}\text { 06: deciduous } \\
\text { needleleaf trees }\end{array}$ & $-1.2 \times 10^{-1}$ & $1.2 \times 10^{0}$ & $7.1 \times 10^{-1}$ & $4.8 \times 10^{0}$ & $-5.1 \times 10^{0}$ & $1.8 \times 10^{0}$ & $-1.6 \times 10^{0}$ & $6.6 \times 10^{1}$ & $-1.7 \times 10^{1}$ & $7.7 \times 10^{0}$ & $-1.5 \times 10^{1}$ & $7.8 \times 10^{0}$ \\
\hline $\begin{array}{l}07 \text { : deciduous } \\
\text { broadleaf trees }\end{array}$ & $1.6 \times 10^{-2}$ & $3.4 \times 10^{-1}$ & $4.5 \times 10^{-1}$ & $1.8 \times 10^{0}$ & $-2.0 \times 10^{-1}$ & $-5.3 \times 10^{-1}$ & $-2.2 \times 10^{0}$ & $3.9 \times 10^{1}$ & $-6.7 \times 10^{0}$ & $6.2 \times 10^{0}$ & $-1.2 \times 10^{1}$ & $6.1 \times 10^{0}$ \\
\hline $\begin{array}{l}\text { 11: deciduous } \\
\text { shrubs }\end{array}$ & $5.6 \times 10^{-2}$ & $1.6 \times 10^{-1}$ & $2.8 \times 10^{-1}$ & $7.4 \times 10^{-1}$ & $1.7 \times 10^{0}$ & $-1.4 \times 10^{0}$ & $-2.2 \times 10^{0}$ & $2.7 \times 10^{1}$ & $-2.7 \times 10^{0}$ & $7.7 \times 10^{0}$ & $-1.4 \times 10^{1}$ & $7.4 \times 10^{0}$ \\
\hline 14: long grass & $-7.9 \times 10^{-2}$ & $1.0 \times 10^{0}$ & $6.6 \times 10^{-1}$ & $5.1 \times 10^{0}$ & $-4.2 \times 10^{0}$ & $9.9 \times 10^{-1}$ & $-2.0 \times 10^{0}$ & $6.3 \times 10^{1}$ & $-1.6 \times 10^{1}$ & $1.1 \times 10^{1}$ & $-2.0 \times 10^{1}$ & $1.1 \times 10^{1}$ \\
\hline 15: crops & $-6.0 \times 10^{-2}$ & $1.0 \times 10^{0}$ & $6.5 \times 10^{-1}$ & $3.4 \times 10^{0}$ & $-2.4 \times 10^{0}$ & $3.4 \times 10^{-1}$ & $-2.0 \times 10^{0}$ & $6.2 \times 10^{1}$ & $-1.5 \times 10^{1}$ & $7.9 \times 10^{0}$ & $-1.5 \times 10^{1}$ & $8.0 \times 10^{0}$ \\
\hline 16: rice & $-6.0 \times 10^{-2}$ & $1.0 \times 10^{0}$ & $6.5 \times 10^{-1}$ & $3.2 \times 10^{0}$ & $-2.1 \times 10^{0}$ & $2.3 \times 10^{-1}$ & $-2.0 \times 10^{0}$ & $6.2 \times 10^{1}$ & $-1.5 \times 10^{1}$ & $7.7 \times 10^{0}$ & $-1.5 \times 10^{1}$ & $7.8 \times 10^{0}$ \\
\hline 17: sugar & $7.5 \times 10^{-2}$ & $1.2 \times 10^{-1}$ & $2.4 \times 10^{-1}$ & $3.6 \times 10^{-1}$ & $1.6 \times 10^{0}$ & $-1.1 \times 10^{0}$ & $-2.1 \times 10^{0}$ & $2.4 \times 10^{1}$ & $-1.8 \times 10^{0}$ & $6.5 \times 10^{0}$ & $-1.2 \times 10^{1}$ & $6.3 \times 10^{0}$ \\
\hline 18: maize & $5.6 \times 10^{-2}$ & $1.6 \times 10^{-1}$ & $2.8 \times 10^{-1}$ & $6.6 \times 10^{-1}$ & $1.4 \times 10^{0}$ & $-1.1 \times 10^{0}$ & $-2.2 \times 10^{0}$ & $2.7 \times 10^{1}$ & $-2.6 \times 10^{0}$ & $6.5 \times 10^{0}$ & $-1.2 \times 10^{1}$ & $6.3 \times 10^{0}$ \\
\hline 19: cotton & $7.5 \times 10^{-2}$ & $1.2 \times 10^{-1}$ & $2.4 \times 10^{-1}$ & $3.6 \times 10^{-1}$ & $1.6 \times 10^{0}$ & $-1.1 \times 10^{0}$ & $-2.1 \times 10^{0}$ & $2.4 \times 10^{1}$ & $-1.8 \times 10^{0}$ & $6.5 \times 10^{0}$ & $-1.2 \times 10^{1}$ & $6.3 \times 10^{0}$ \\
\hline
\end{tabular}

$V_{\mathrm{ds}}\left(\mathrm{PM}_{10+}\right)=$

$\left(d_{1} u_{*}+d_{2} u_{*}^{2}+d_{3} u_{*}^{3}\right) e^{\left(f_{1} u_{*}+f_{2} u_{*}^{2}+f_{3} u_{*}^{3}\right)\left(\frac{\mathrm{LAI}}{\mathrm{LAI} I_{\max }}-1\right)}$.

where $d_{1}, d_{2}, d_{3}, f_{1}, f_{2}$ and $f_{3}$ are the LUC-dependent empirical constants and are also shown in Table $2 \mathrm{a}$ and $\mathrm{b}$. The bulk $V_{\mathrm{d}}$ for $\mathrm{PM}_{10+}$ can then be calculated as

$$
V_{\mathrm{d}}\left(\mathrm{PM}_{10+}\right)=V_{\mathrm{g}}\left(\mathrm{PM}_{10+}\right)+\frac{1}{R_{\mathrm{a}}+1 / V_{\mathrm{ds}}\left(\mathrm{PM}_{10+}\right)},
$$

Using the same approach as in Sect. 3.2, a comparison of $V_{\mathrm{ds}}\left(\mathrm{PM}_{10+}\right)$ from using Eqs. (10) and (11) and from the original scheme is conducted (figure not provided), and a comparison of $V_{\mathrm{d}}\left(\mathrm{PM}_{10+}\right)$ between the new (Eq. 12) and the original scheme (Eq. 1) is also conducted (figure not provided). Similar to what was found for $\mathrm{PM}_{2.5-10}, V_{\mathrm{ds}}\left(\mathrm{PM}_{10+}\right)$ calculated using the newly developed equations agrees within $\sim 10 \%$ of the original scheme over most LUCs and within $\sim 20 \%$ over a few LUCs $(22,24) . V_{\mathrm{d}}\left(\mathrm{PM}_{2.5-10}\right)$ values from the new scheme were also within 10-20\% difference over all the LUCs. Again, such small percentage differences were considered acceptable in practical applications.

\subsection{Uncertainties caused by pre-assumed size distributions}

The new algorithm was developed with the assumption that the pre-assumed lognormal size distributions are accurate. The two parameters, $d_{\mathrm{m}}$ and $\sigma$, used for the pre-assumed lognormal size distributions were based on measurements found in the literature and were thought to best represent the size distributions of mostly concerned particulate species (Zhang et al., 2008). To investigate how sensitive the new algorithm is to the choice of $d_{\mathrm{m}}$ and $\sigma$, sensitivity tests were conducted using reasonable ranges of values of these two parameters.

For $\mathrm{PM}_{2.5}$ (Fig. 6a), if $\sigma$ does not change, but the sizedistribution profile shifts to smaller sizes (red color), $V_{\mathrm{ds}}$ increases by $20-30 \%$; and if it shifts to the larger sizes (blue color), $V_{\mathrm{ds}}$ decreases by $<20 \%$. This can be explained by the size-dependent $V_{\mathrm{ds}}$ (i.e., increases with the decreasing size for submicron and ultrafine particles). If the mode of the size distribution does not change, but the width of the profile increases or decreases (green or black color), $V_{\mathrm{ds}}$ decreases or increases by $\sim 10 \%$. Again, this can be explained by the size-dependent $V_{\mathrm{ds}}$ (note the $V$-shaped $V_{\mathrm{ds}}$ profile around the $1 \mu \mathrm{m}$ size in Zhang et al., 2001). Thus, the uncertainties in the new algorithm caused by the pre-assumed lognormal size distribution should be on the order of $\sim 20 \%$, which is much smaller than other known uncertainties.

For $\mathrm{PM}_{2.5-10}$ (Fig. 6b), $V_{\mathrm{ds}}$ increases with increasing particle size. Shifting the size-distribution profile to larger (or smaller) sizes (blue or read color) increases (or decreases) $V_{\mathrm{ds}}$ by $\sim 50 \%$. Increasing the width of the profile (green color) can increase $V_{\mathrm{ds}}$ by a factor of 2.0 or slightly larger. Thus, the uncertainties in the new algorithm caused by the pre-assumed lognormal size distribution should be on the order of a factor of 2.0 in most cases, which is comparable to other known uncertainties in most existing schemes. A similar conclusion is found for $\mathrm{PM}_{10+}$.

\section{Conclusions}

Monitoring networks have been established around the world to quantify atmospheric deposition of criteria pollutants to various ecosystems where the dry deposition component is estimated as a product of monitored air concentration and calculated $V_{\mathrm{d}}$ of pollutants of interest. For aerosol particles, several size-resolved $V_{\mathrm{d}}$ schemes are available in the literature that can be applied to any particle species and over any different surfaces, but this is not the case for bulk aerosol particles, which are monitored in various networks. To fill this gap, a new algorithm is developed taking a widely used size-resolved $V_{\mathrm{d}}$ scheme as the benchmark. The new algorithm produces similar $V_{\mathrm{d}}$ values to the original size-resolved scheme for fine, coarse and giant particles 
with uncertainties on the order of $20 \%$ or less if the actual particle size distributions are close to the ones assumed in this study. The new scheme is easier to use than the original one at monitoring locations where air concentrations are monitored for quantifying atmospheric dry deposition. If the mass fractions in fine, coarse and giant particles are known or can be assumed for a particle species, its bulk $V_{\mathrm{d}}$ can then be obtained by weighting $V_{\mathrm{d}}\left(\mathrm{PM}_{2.5}\right), V_{\mathrm{d}}\left(\mathrm{PM}_{2.5-10}\right)$ and $V_{\mathrm{d}}\left(\mathrm{PM}_{10+}\right)$. The uncertainties in $V_{\mathrm{d}}$ from the new scheme are similar to those from the more sophisticated size-resolved schemes.

Edited by: J. G. Murphy

\section{References}

Feng, J.: A size-resolved model and a four-mode parameterization of dry deposition of atmospheric aerosols, J. Geophys. Res., 113, D12201, doi:10.1029/2007JD009004, 2008.

Fowler, D., Pilegaard, K., Sutton, M. A., Ambus, P., Raivonen, M., Duyzer, J., Simpson, D., Fagerli, H., Fuzzi, S., Schjoerring, J. K., Granier, C., Neftel, A., Isaksen, I. S. A., Laj, P., Maione, M., Monks, P. S., Burkhardt, J., Daemmgen, U., Neirynck, J., Personne, E., Wichink-Kruit, R., Butterbach-Bahl, K., Flechard, C., Tuovinen, J. P., Coyle, M., Gerosa, G., Loubet, B., Altimir, N., Gruenhage, L., Ammann, C., Cieslik, S., Paoletti, E., Mikkelsen, T. N., Ro-Poulsen, H., Cellier, P., Cape, J. N., Horvath, L., Loreto, F., Niinemets, U., Palmer, P. I., Rinne, J., Misztal, P., Nemitz, E., Nilsson, D., Pryor, S., Gallagher, M. W., Vesala, T., Skiba, U., Brueggemann, N., Zechmeister-Boltenstern, S., Williams, J., O'Dowd, C., Facchini, M. C., de Leeuw, G., Flossman, A., Chaumerliac, N., and Erisman, J. W.: Atmospheric composition change: Ecosystems-Atmosphere interactions, Atmos. Environ., 43, 5193-5267, 2009.

Gallagher, M. W., Beswick, K. M., Duyzer, J., Westrate, H., Choularton, T. W., and Hummelshoj, P.: Atmospheric particles and their interactions with natural surfaces, in: BiosphereAtmosphere Exchange of Pollutants and Trace Substances, Experimental and Theoretical Studies of Biogenic Emissions and of Pollutant Deposition, 4, 45-93, edited by: Slanina, S., SpringerVerlag, New York, 1997.

Gallagher, M. W., Nemitz, E., Dorsey, J. R., Fowler, D., Sutton, M. A., Flynn, M., and Duyzer, J.: Measurements and parameterizations of small aerosol deposition velocities to grassland, arable crops, and forest: Influence of surface roughness length on deposition, J. Geophys. Res., 107, 4154, doi:10.1029/2001JD000817, 2002.

Giorgi, F.: A particle dry-deposition parameterization scheme for use in tracer transport models, J. Geophys. Res., 91, 9794-9806, 1986.

Kouznetsov, R. and Sofievm, M.: A methodology for evaluation of vertical dispersion and dry deposition of atmospheric aerosols, J. Geophys. Res., 117, D01202, doi:10.1029/2011JD016366, 2012.

Lamaud, E., Fontan, J., Lopez, A., and Druilhet, A.: Parametrization of the dry deposition velocity of submicronic aerosol particles. International Conference on Air Pollution - Proceedings, Barcelona, Spain, 27-29 September 1994, 2, 433-440, 1994.
Nemitz, E.: Surface/atmosphere exchange of atmospheric acids and aerosols, including the effect and model treatment of chemical interactions. Background document from the COST éclair workshop, Paris, 25-27 September, available at: https://colloque.inra. fr/cost_eclaire/Background-documents (last access: 24 September 2013), 2012.

Nho-Kim, E.-Y., Michou, M., and Peuch V.-H.: Parameterization of size-dependent particle dry deposition velocities for global modeling, Atmos. Environ., 38, 1933-1942, 2004.

Nicholson, K. W.: The dry deposition of small particles: A review of experimental measurements, Atmos. Environ., 22, 2653-2666, 1988.

Petroff, A. and Zhang, L.: Development and validation of a size-resolved particle dry deposition scheme for application in aerosol transport models, Geosci. Model Dev., 3, 753-769, doi:10.5194/gmd-3-753-2010, 2010.

Petroff, A., Mailliat, A., Amielh, M., and Anselmet, F.: Aerosol dry deposition on vegetative canopies. Part I: Review of present knowledge, Atmos. Environ., 42, 3625-3653, 2008.

Pryor, S., Gallagher, M., Sievering, H., Larsen, S., Barthelmie, R., Birsan, F., Nemitz, E., Rinne, J., Kulmala, M., Grönholm, T., Taipale, R., and Vesala, T.: A review of measurement and modelling results of particle atmosphere-surface exchange, Tellus B, 60, 42-75, 2008.

Ruijgrok, W., Davidson, C. I., and Nicholson, K. W.: Dry deposition of particles: implications and recommendations for mapping of deposition over Europe, Tellus, 47, 587-601, 1995.

Ruijgrok, W., Tieben, H., and Eisinga, P.: The dry deposition of particles to a forest canopy: A comparison of model and experimental results, Atmos. Environ., 31, 399-415, 1997.

Sehmel, G. A.: Particle and gas dry deposition: A review, Atmos. Environ., 14, 983-1011, 1980.

Sehmel, G. A. and Hodgson, W. H.: A model for predicting dry deposition of particles and gases to environmental surfaces, AIChE Sym. S., 76, 218-230, 1980.

Sievering, H.: The dry deposition of small particles: A review of experimental measurement, Atmos. Environ., 23, 2863-2864, 1989.

Slinn, W. G. N.: Predictions for particle deposition to vegetative canopies, Atmos. Environ., 16, 1785-1794, 1982.

Wesely, M. L., Cook, D. R, Hart, R. L. and Speer, R. E.: Measurements and parameterization of particulate sulfur dry deposition over grass, J. Geophys. Res., 90, 2131-2143, 1985.

Zhang, L. and Vet, R.: A review of current knowledge concerning size-dependent aerosol removal, China Part., 4, 272-282, 2006.

Zhang, L., Gong S., Padro J., and Barrie L. A.: A size-segregated particle dry deposition scheme for an atmospheric aerosol module, Atmos. Environ., 35, 549-560, 2001.

Zhang, L., Brook, J. R., and Vet, R.: A revised parameterization for gaseous dry deposition in air-quality models, Atmos. Chem. Phys., 3, 2067-2082, doi:10.5194/acp-3-2067-2003, 2003.

Zhang, L., Vet, R., Wiebe, A., Mihele, C., Sukloff, B., Chan, E., Moran, M. D., and Iqbal, S.: Characterization of the sizesegregated water-soluble inorganic ions at eight Canadian rural sites, Atmos. Chem. Phys., 8, 7133-7151, doi:10.5194/acp-87133-2008, 2008.

Zhang, L., Fang, G. C., Liu, C. K., Huang, Y. L., Huang, J. H., and Huang, C. S.: Dry deposition fluxes and deposition velocities of seven trace metal species at five sites in central Taiwan - a 
summary of surrogate surface measurements and a comparison with model estimations, Atmos. Chem. Phys., 12, 3405-3417, doi:10.5194/acp-12-3405-2012, 2012.
Zufall, M. J. and Davidson, C. I.: Dry deposition of particles. in: Atmospheric particles, edited by: Harrison, R. M. and Van Grieken, R. E., John Wiley \& Sons, Chichester, UK, chap. 13, 425-473, 1998. 